\title{
Design of indicators for measuring product performance in the circular economy
}

\section{Steve Cayzer, Percy Griffiths \& Valentina Beghetto}

To cite this article: Steve Cayzer, Percy Griffiths \& Valentina Beghetto (2017): Design of indicators for measuring product performance in the circular economy, International Journal of Sustainable Engineering, DOI: 10.1080/19397038.2017.1333543

To link to this article: http://dx.doi.org/10.1080/19397038.2017.1333543

$$
\text { 曲 Published online: } 26 \text { Jun } 2017 .
$$

Submit your article to this journal $\pi$

View related articles ¿

View Crossmark data $\asymp$ 


\title{
Design of indicators for measuring product performance in the circular economy
}

\author{
Steve Cayzera ${ }^{a}$ Percy Griffiths ${ }^{a}$ and Valentina Beghetto ${ }^{b}$ \\ ${ }^{a}$ Mechanical Engineering, University of Bath, Bath, UK; bepartment of Molecular Science and Nanosystems, Universita Ca Foscari, Mestre, Venezia, Italy
}

\begin{abstract}
This paper explores measurement of product performance with respect to circular economy (CE) principles. Potential indicators are assessed with special attention given to questions such as: the variables that should be measured; how these variables should be assessed; and in which format they should be presented. The resulting considerations are used to develop a prototype whose design is informed through feedback from CE experts. The prototype uses a points-based questionnaire which converges into a simple final result with minimum and maximum limits. The selected approach is critically appraised, and its utility for decision-making discussed. The prototype is tested against a product in the chemical processing industry. The strengths include: ease of use; simplicity; speed; and an effective metaphor for the diffusion of CE principles. The limitations include: the opaque and potentially misleading nature of a single metric; superficial engagement with decision-making; and the reliance on context-specific assumptions. Future developments could include refining the approach to encourage deeper reflection, and generalisation of the approach to different industry sectors or sustainability frameworks.
\end{abstract}

ARTICLE HISTORY

Received 31 August 2016 Accepted 6 April 2017

\section{KEYWORDS}

Circular economy; metrics

\section{Introduction}

This paper considers the assessment of a product with respect to a 'Circular Economy' (CE) principle. According to the Ellen MacArthur Foundation (EMF) (2012), the CE contrasts with the dominant economic paradigm of a 'Linear Economy' (LE); a chain of activities dependent on the extraction of raw natural resources. CE has significant traction, with explicit policy in China (Geng et al. 2013) and Europe (European Commission 2015). The EMF itself has attracted global partners including Google, Unilever, Nike, Cisco, Philips and Renault (EMF 2015) thus confirming its status as an integrative and leading force around the CE topic.

\section{Theoretical roots}

Circular thinking has a long history (Boulding 1966) and the analogy of industrial metabolism (Ayres and Kneese 1969) is well established. CE models are built on the foundation of decades of research in such fields as Industrial Ecology (Erkman 1997), the Performance Economy (Stahel 2010), the Blue Economy (Pauli 2010) and Cradle to Cradle (Braungart and McDonough 2009). The EMF explicitly acknowledges these schools of thoughts in its 'CE Principles' (EMF 2012). The metrics presented in this paper conform to these principles, and are thus intended to have relevance for the underlying models.

It could be argued that the EMF approach is somewhat Eurocentric; Gregson and Crang (2015) argue that circular economies (plural) should be viewed in a global context. Using the notion of value recovery, they differentiate between hi-tech, capital-intensive approaches (promoted by the EMF interpretation) and labour-intensive approaches; arguing that the latter may serve a wider range of global markets.

\section{The EMF notion of a CE}

Figure 1 depicts the EMF conceptualisation of a CE (EMF 2012), suggesting the preservation of value, or revalorization (Parkinson and Thompson 2003) through activities like reuse, refurbishment and remanufacturing.

EMF suggests a number of approaches for revalorisation through its CE principles (EMF 2012) including:

- Design out waste; treat waste as a resource;

- Design for disassembly; standardise and modularise;

- Select feedstock materials based on circularity potential;

- Promote resilience through diversity;

- Obtain energy from renewable sources;

- Think in 'systems' and cascades.

Ken Webster is the head of innovation at the EMF and one of the interviewees in this study. According to Webster (2013, personal communication 2014), this last principle underlies the entire philosophy of the EMF and hence is worth exploring in a little more detail. Systems thinking, for Webster, involve moving away from a 'mechanistic' view of the world where concepts like waste are widely accepted to a new 'systemic' mind-set that performs as a 'living system' where everything 


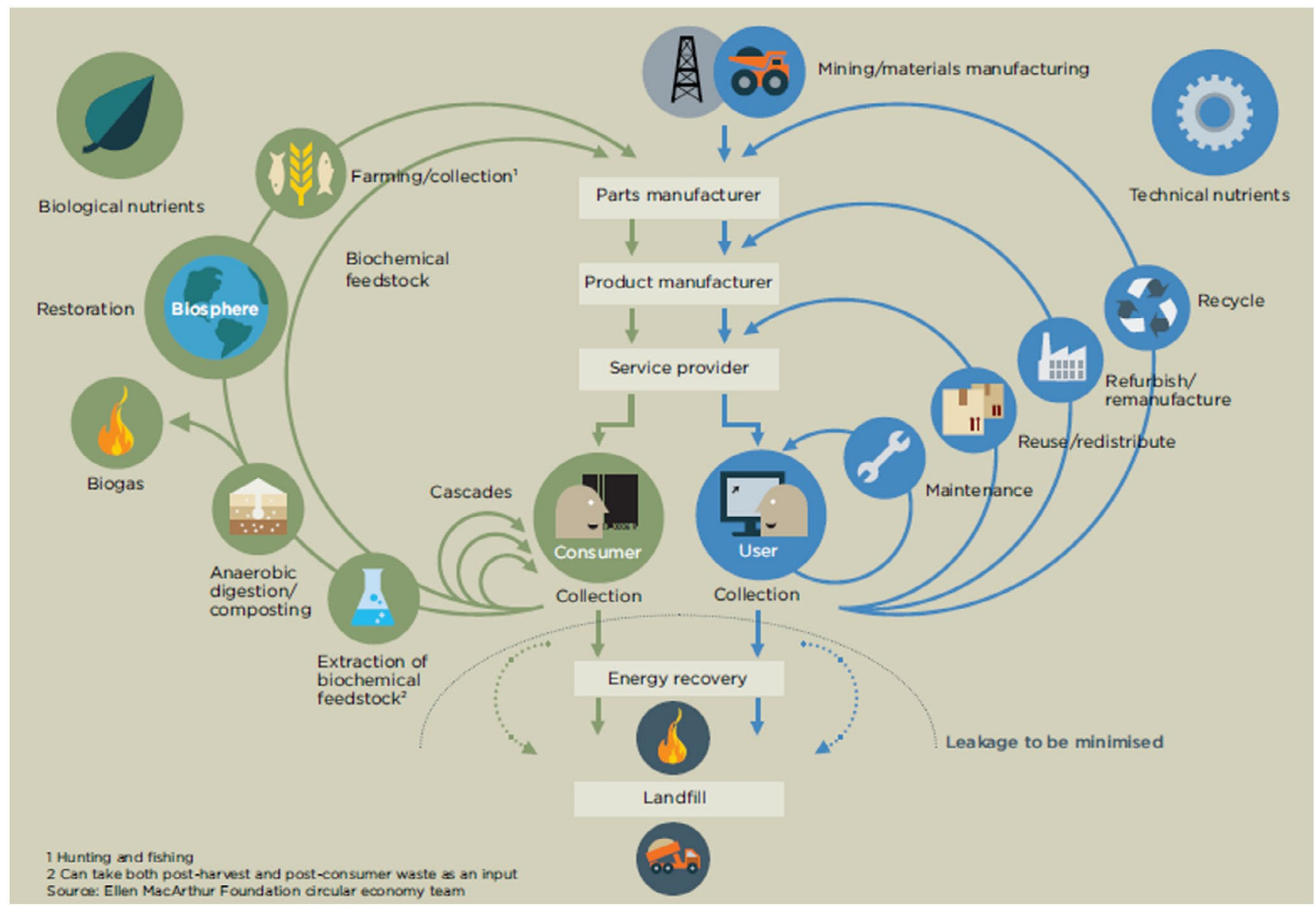

Figure 1. The EMF conceptualisation of a Circular Economy, showing two types of feedback loop: technical and biological (EMF (Ellen MacArthur Foundation) 2012), figure used with permission.

is connected, nothing is wasted and the relation between the parts always matter. Webster argues that local actions are vulnerable to the effects of the so-called 'prisoner's dilemma', where locally beneficial actions combine to a globally deleterious outcome. Hence, the $\mathrm{CE}$ involves systemic thinking; in space (supply chain locations); in time (cradle to cradle); and in context (economic and psychological factors). Webster thus advocates a focus on feedback dynamics (moving to regeneration of capital) rather than individual gestures (limiting capital loss).

\section{Circular Economy indicators}

In order to assess whether $\mathrm{CE}$ principles are leading to meaningful change, it is necessary to develop a measurement system (Geng et al. 2013). Indicators have the 'ability to summarise, focus and condense the enormous complexity of our dynamic environment to a manageable amount of meaningful information' (Geoffrey and Todd 2001). Church and Rogers (2006) refer to indicators as 'means to measure change' so they can be used for managing the transition to $\mathrm{CE}$. $\mathrm{CE}$ indicators could work to: inform policy; promote literacy around the CE topic; enable new quality standards; and compare businesses for sustainability investment indexes and markets. However, Beratan et al. (2004) warn that indicators must be connected to decision-making and implementation. Thus, indicators do not in themselves achieve a successful transition to a CE, but are an important tool for aiding progress towards this goal.

\section{Existing CE indicators}

Sustainability indicators are many and varied. Many of them (for example, FTSE4Good) are focused at a company level rather than a product level. Rahdari and Anvary Rostamy (2015) present a review of company level sustainability indicators, showing how they cover social, environmental and governance aspects of a company's performance. Nappi and Rozenfeld (2015) show how internal company metrics (for example $\%$ of products created with eco-design principles) can be incorporated into a performance management system. Franklin-Johnson, Figge, and Canning (2016) however argue that burden-based (i.e. damage limitation) indicators are inadequate for assessing circularity.

Indicators that specifically focus on circularity are at an earlier stage of development (Giurco et al. 2014). Many indicators are at a national rather than product level (Åkerman 2016; EASAC 2016). Perhaps the most high profile of these comes from China, where the government applies well-known assessment methods to measure the performance of their CE policies (e.g. Life Cycle Assessment, eco-efficiency and carbon footprint). While illustrating the political impact of CE thinking, Geng et al. (2013) acknowledge that these indicators 'weren't designed for the systemic, closed-loop, feedback features that characterize CE'. 
Other circularity indicators are reviewed by Ghisellini, Cialani, and Ulgiati (2016) who note that many of these are at a supra company level, for example, eco-industrial parks.

At the company level, Scheepens, Vogtländer, and Brezet (2016) describe the application of the eco-costs-value ratio (EVR) model (Vogtländer, Brezet, and Hendriks 2001) to CE innovations, particularly product service systems. One of the motivations of this work is to measure added customer value of a 'circular' product, not only because this makes it commercially feasible, but also because maintaining (or increasing) the price guards against rebound effects. The focus of this work is on business model design rather than product design.

At the product level, there are a number of ways to improve circularity. For example: switching to longer lasting products; modularisation and remanufacturing; component reuse; and designing products with less material. Materials used should be free of toxic chemicals, designed for easy disassembly and capable of being recycled or composted. Kjaer et al. (2016) discuss the various complexities involved with measuring the intangible effects of product innovation including behavioural change. They propose a range of tools, including (extended) life cycle assessment, system dynamics and simulation tools. Another possibility is to take a thermodynamic approach and measure exergy or 'Entropic Overhead' (Sustainable Brands 2013).

At the product design level (the focus of this paper), FranklinJohnson, Figge, and Canning (2016) describe a method of assessing products based on longevity. This is simple and accessible but only partially addresses CE principles described above. A more comprehensive approach has been taken by the EMF, who (together with IDEO) have recently unveiled a circular design guide (EMF 2016). This guide provides a number of methods and tools aligned with different stages on the product journey (Understand - Define - Make - Release). The work described here predates that guide, and differs in that our tool is designed to assess existing products in a simple and user friendly way, rather than take designers on an educational journey. A closer analogue is the CE Toolkit developed at the University of Cambridge (Evans and Bocken 2013) which provides a web interface and a range of questions covering the product lifecycle. Our tool is similar in approach and thus will be compared to the CE Toolkit in the discussion.

Another example comes from Europe, where the European Commission Environment Program partnered with the EMF and Granta Design on the LIFE + Project (Granta Design 2015). The LIFE + CE indicators include a 'Material Circularity Indicator (MCI)' as well as complementary indicators for toxicity, scarcity and energy. MCI has now been incorporated into a commercial offering. The development of the MCI included a pilot project with the home improvement retailing company Kingfisher, testing the approach on real products. The resulting prototype is called 'Kingfisher Circularity Calculator' (KCC) on which the prototype described in this paper is built.

\section{Methodology}

This paper attempts to answer the research question: What are suitable characteristics of indicators for measuring the performance of products within the EMF CE model?
In order to address this question, this paper takes the following approach: an initial phase where the EMF CE principles are used as a base from which relevant and measurable variables are derived, together with ideal targets. A second phase where the KCC is extended into a CE indicator prototype (CEIP), the design of which is based on a literature review supplemented with a first round of 45-60 min-long semi-structured interviews made in June, July and August 2014 with subjects shown in Table 1. The CEIP is initially intended to be used by manufacturing and/or retail companies of tangible goods with access to bill of materials. They would use the CEIP to measure and evaluate the performance of their products against the EMF CE principles. A third phase where the CEIP is tested with a panel of potential users (P2, P3 and P8 from Table 1) via a second round of interviews and questionnaires and challenged with a real case study.

The main objectives of the first round of interviews were (i) to get a deep understanding of the CE model and its principles, (ii) to gather expectations of characteristics for a potential prototype of CE indicators, (iii) to generate a benchmark of other indicators that could be useful for the design of the prototype and (iv) to capture the most possible heterogeneous range of perceptions of the status of CE model and CE indicators and the actual use of sustainable indicators in different private business scenarios. These objectives were achieved by a universe of nine interviewers' profiles, a sufficient number given the ad hoc nature of the study (National Centre for Research Methods (NCRM) 2015). These interviewees are chosen on the basis of their relationship with, or interest in, CE and their diverse sectoral backgrounds. An overview of the scope of the questions can be seen in Table 2 . The first round of interviews involved general questions to all participants and additional, company-specific questions. The second round of interviews were concerned with feedback on the prototype.

Semi-structured interviews were chosen as the most appropriate method in the second and third phases because they propose sufficient freedom for the interviewer to deliver their opinions through the use of open questions.

During the second phase, KCC was used as a reference source because it is a product design tool specifically rooted with EMF CE principles. In terms of content, the KCC presents ten questions but doesn't present the relation between the CE principles and the CE variables. Also, KCC questions don't show any clear relationship with the lifecycle stages of the product. Although the presentation of this relationship may not be necessarily important it may aid the user to have a clearer and faster understanding of what is being assessed. The only moment where the relationship of the product with its lifecycle stages is showed in the KCC is at the moment of the presentation of the results. However, the nature of one of those lifecycle stages, 'Reduce Waste', could be challenged because it doesn't necessarily relate to a lifecycle stage of a product and could be more related to a group of actions, intentions or features.

In terms of format, the KCC presents the general information of the product, the questionnaire and the results in one MS Excel page. There is not a clear separation of questions and answers and the user may need some time to understand the tool.

The CEIP was designed in MS Office Excel after extending the KCC through the following steps: 
Table 1. Interviewees participating in Phase 1 of the research. All interviews were conducted by skype with the exception of P1 and P9 which were face-to-face.

\begin{tabular}{|c|c|c|c|c|c|}
\hline \multicolumn{6}{|c|}{ Participants } \\
\hline \# & Name & Organisation & Charge & Profile & Origin \\
\hline P1 & Ken Webster & Ellen MacArthur Foundation & Head of Innovation & $\begin{array}{l}\text { More than } 15 \text { years of experience in } \\
\text { Environmental topics. He is the main } \\
\text { curator of CE model in the Foundation }\end{array}$ & UK \\
\hline P2 & Chris Tuppen & Advancing Sustainability & Founder & $\begin{array}{l}\text { More than } 20 \text { years of experience in } \\
\text { Sustainability topics and } 50 \text { published } \\
\text { papers. Fellow of the Royal Society } \\
\text { of Arts, member of the Institute of } \\
\text { Physics }\end{array}$ & UK \\
\hline P3 & Michael Whitley & 3 MW Circular Economy Consultancy & Founder & $\begin{array}{l}\text { Previously reponsible for Supply Chain } \\
\text { and Business Model Strategy, Hewl- } \\
\text { ett-Packard }\end{array}$ & UK \\
\hline P4 & Ana Pereira & Grante Design & $\begin{array}{l}\text { Project Manager for Education \& } \\
\text { Research }\end{array}$ & $\begin{array}{l}\mathrm{PhD} \text { in Biological Engineering, MSc En- } \\
\text { ergy and Environmental Engineering. } \\
\text { Member of the team that worked in } \\
\text { the development of the } \mathrm{MCl}\end{array}$ & UK \\
\hline P7 & Ignacio Arrospide & AFP Integra & Investment Manager & $\begin{array}{l}\text { Bachelor in Economics and MBA from } \\
\text { Kellog School of Management at } \\
\text { Northwestern University US. More } \\
\text { than } 10 \text { years in investment manage- } \\
\text { ment }\end{array}$ & Peru \\
\hline P8 & Anonymous & $\begin{array}{l}\text { Technology \& Innovation Consultancy } \\
\text { firm }\end{array}$ & Technology \& Innovation Consultant & $\begin{array}{l}\text { More than } 25 \text { years of work experience } \\
\text { in R+D departments of major global } \\
\text { technology brands. Major studies in } \\
\text { Microelectronics and Physics }\end{array}$ & UK \\
\hline P9 & Andre Fourie & SAB Miller & Senior Manager, Environmental Value & $\begin{array}{l}\text { More than } 15 \text { years of experience in } \\
\text { Sustainability Topics in the Beverage } \\
\text { Industry }\end{array}$ & UK \\
\hline
\end{tabular}

Table 2. Scope and intention of interview questions.

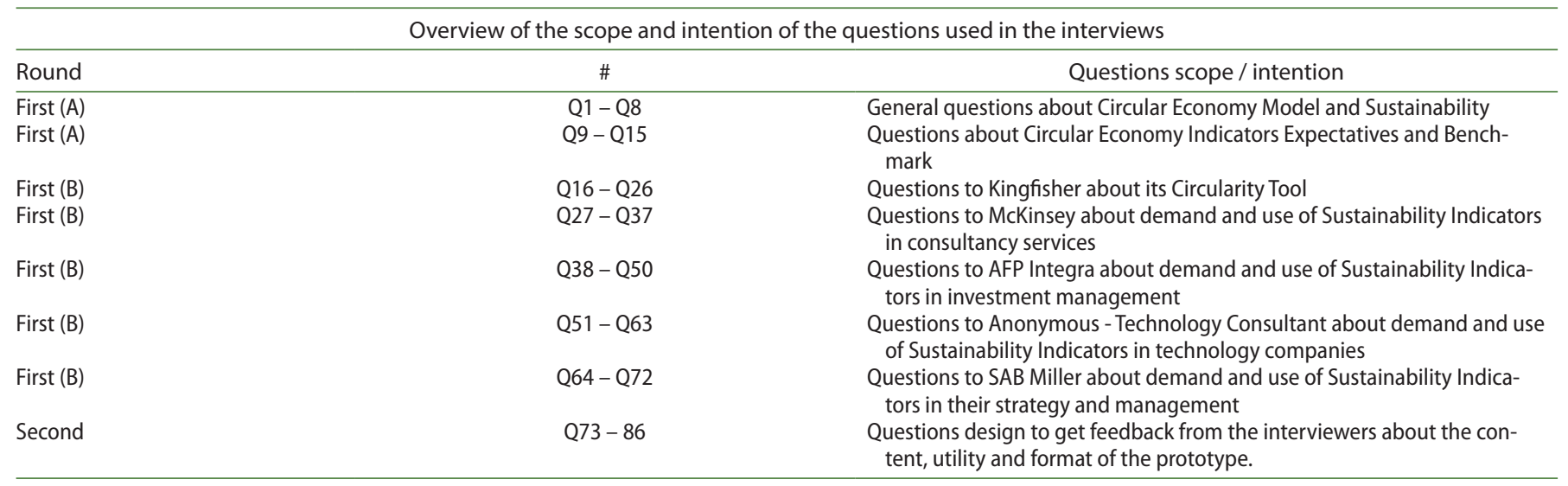

(1) Step 1-Q\&A criteria configuration: the criteria of the Q\&A of CEIP is very similar to the criteria of the KCC where every variable should be evaluated with one question. Furthermore, the responses to the question are not open and they are pre-designed. Every question has an ideal response option which is assigned all the available points for that question. In the same way, every question has a least preferred response option which doesn't take any available points.

(2) Step 2 - Question Design: the questions should be highly focused in evaluating the performance of the product within the $\mathrm{CE}$ principles/ categories. Each product lifecycle stage includes specific questions for that particular stage. This approach is the same in KCC and CEIP. The CEIP contains 15 questions in total, 10 from KCC and 5 new (Table 3 ).

(3) Step 3 - Answer Options Design: the answer options signify a key design step because they represent the alternatives that create the scale from being 'non-circular at all' to being 'the ideal circular option'. Thus, the creation of the answer options starts with the definition of the 'Ideal Final Result' (IFR) of the variable that is 
INTERNATIONAL JOURNAL OF SUSTAINABLE ENGINEERING 5

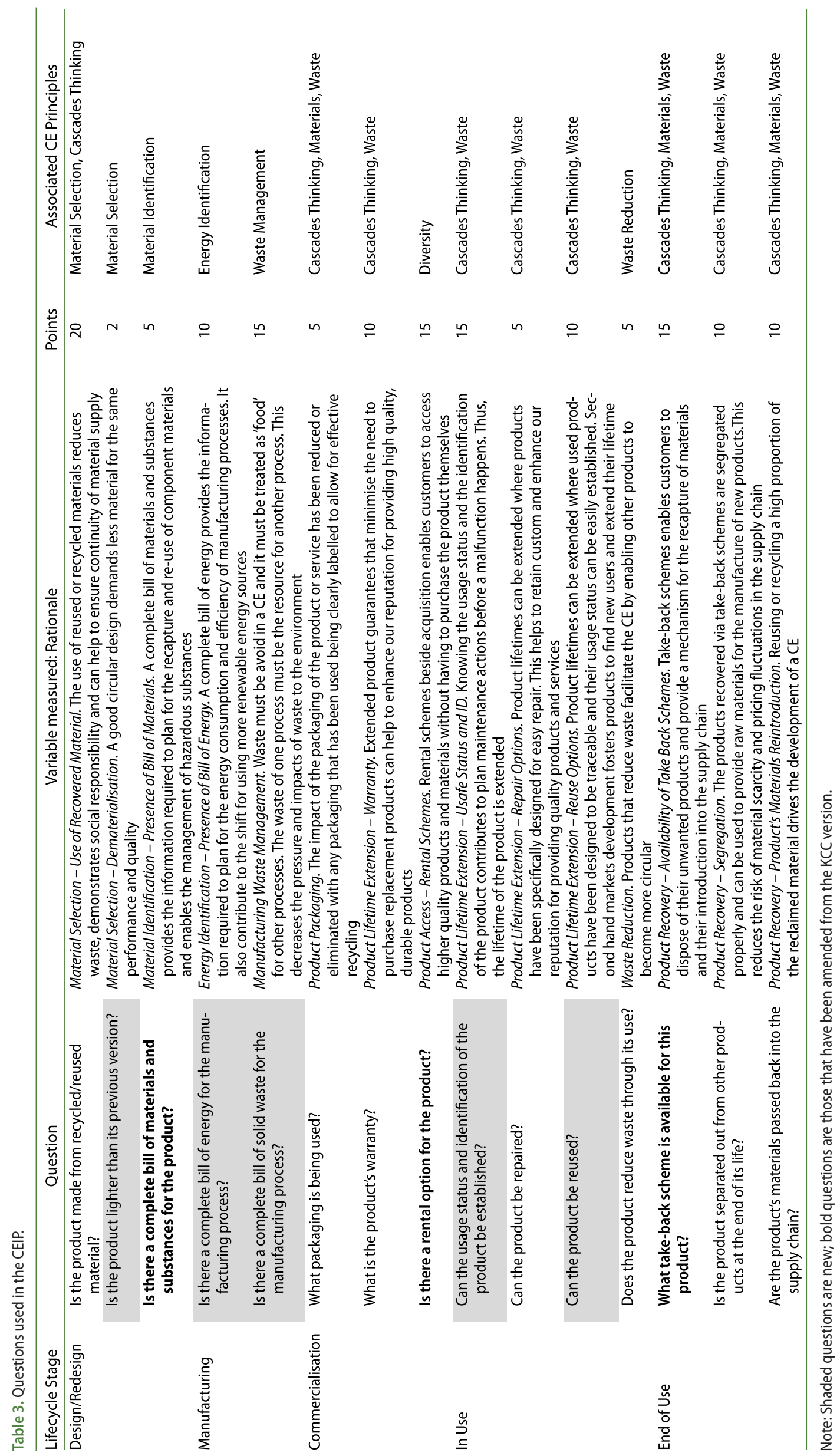




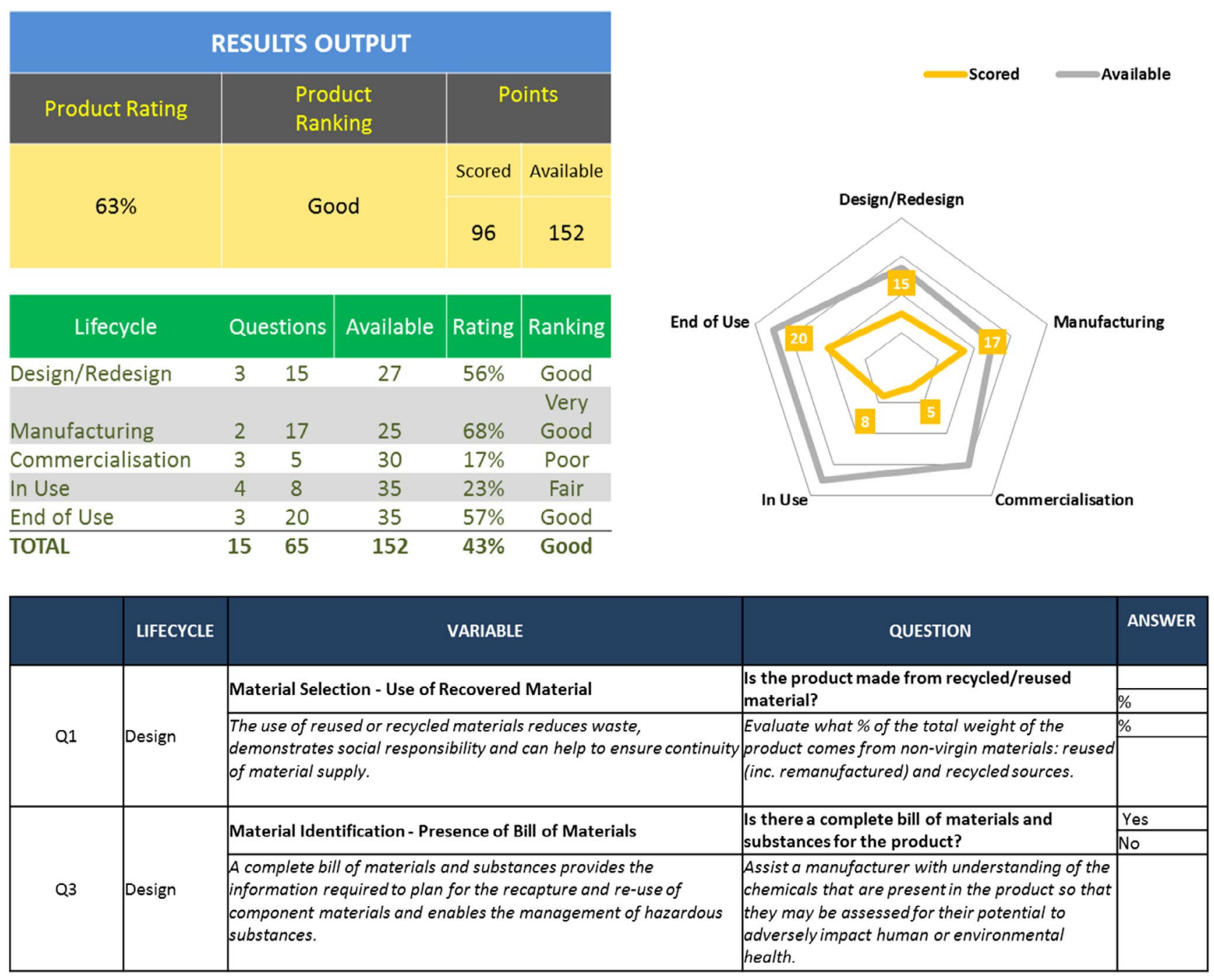

Figure 2. Selected part of the CEIP interface.

being addressed. For this example, the IFR was defined using the insights from the interviews, the literature review and the benchmark of the KCC. The response options are intended to form a coherent and reasonable scale of improvements from the less circular option to the circular IFR. Due to the 'openness' nature of the question, several options can be designed, thus, a selection process must be carried out to deliver the most representative ones. Also, the responses should intend to be the most general possible in order to be able to evaluate products from different industries and contexts. This condition was perhaps one of the most difficult challenges while designing the responses options.

(4) Step 4 - Weighting: The first decision corresponds to define how much points from the available points of the test (152 points maximum) should correspond to each variable/question. The rationale that was followed was basically to intend distribution of an equal amount of points to each lifecycle stage of the products. However, from the five lifecycle stages, it was inferred by the literature review and the interviews that some of the stages are slightly more relevant to the CE principles than others. So for example, lifecycle stages like 'In Use' and 'End of Use' got 35 points each one to distribute within their variables. It is assumed that actions within those stages would produce bigger impacts in increasing the performance of products within the CE principles. The final distribution of available points through the lifecycle stages is: Design/Redesign 27 points, Manufacturing 25 points, Commercialisation 30 points, In Use 35 points and End of Use 35 points (Table 3).

A real-life case study is used to challenge CEIP in the third phase where it is also critically evaluated against these questions in a second round of interviews:

- Is this use of a single metric appropriate?

- Does the metric reliably indicate improved environmental outcomes?

- Does the metric lead to improved decision-making? 


\section{Results}

The interviewees identified fifteen possible variables which could be linked to EMF CE principles. These were grouped according to the lifecycle stages of the product to facilitate the understanding of the user (Table 3).

The CEIP was designed by defining a question corresponding to each variable, taking or amending these from the KCC where appropriate. Each question has multiple answer options, with weightings informed by the expert interviews. The questions are grouped by lifecycle stage, with a single aggregated score showing the 'circularity' of the product. The CEIP was designed in MS Excel due to its high level of diffusion across multiple business sectors. The CEIP includes a Summary tab, with a 'Questionnaire' tab containing the fifteen questions.

Figure 2 presents snapshots of the CEIP. The overall score (top left) is expanded to a spider diagram (top right) showing circularity across different parts of the lifecycle (mid-left). The questions (two examples shown in lower half of figure) can be answered with a simple yes/no, but extra bonus points are awarded for $\%$ of non virgin material, or where the bill of materials does not include substances on the nominated critical lists.

\section{User feedback}

The CEIP is based on the KCC, but there are some differences. As well as the five new questions, some answer options include the concept of 'bonus points.' The main objective was to show the companies additional ways to improve. The CEIP has separate pages and clearer instructions. The lifecycle stages and the variables are included next to each question to facilitate the recognition of what it is being assessed in the product. The following comments were made by interview participants about the CEIP:

- The CEIP is 'easy to follow' (P3) 'far more comprehensible' than the KCC (P8).

- The CEIP could be used 'as a training exercise for engineers' (P3) and 'to understand the levers for working on circularization'.

- P3 commented that the CEIP could be useful 'as a checklist' (P3) and could be extended to 'a comparison of 2-3 product versions on one page. P2 cautions that Q4/5 are 'good to include for completeness' but may make it 'more difficult to make an assessment?.

- There were some comments on hidden complexity, for example, P2 noted that 'lighter may mean more carbon intensive materials and/or materials that are more difficult to recycle'

- P3 also commented that the tool is best suited for incremental changes to 'consumer durables'; and therefore less suited to 'throwing away your business model and starting again', and may need a 'future evolution' to be more service focused.

\section{Case study application}

A real-life case study was used to challenge the prototype. The industry in question is leather making. Traditional approaches involve a high level of chrome salts which result in toxic by-products (slurry) requiring landfill. This is both environmentally and financially unsustainable (waste treatment accounts for approximately $5 \%$ of revenue).

The use of chrome poses serious environmental and health problems, due to the formation of carcinogenic $\mathrm{Cr}(\mathrm{VI})$ by-products in the finished articles and in the slurries, not to mention end-of-life problems in recycling and reuse, pushing manufacturers to find innovative solutions.

The substitution of chromium salts has historically been limited due to their ease of use, low cost, high quality and stability of the tanned leather. Active Cross-Linking agents (ACLs) are a promising alternative. ACLs are metal-, formaldehyde-, and phenol-free tanning agents able to give leather of comparable quality to chrome salts, overcoming one of the most critical aspects of all alternative tanning systems known today. ACLs are a library of organic compounds, which can be easily modified and optimised as a function of the specific type of leather produced (footwear, leather goods, garments, etc.).

The industrial application used to challenge the CEIP is a novel ACL for tanning hides, involving both product and process innovation. The application fulfils at least 10 of the 12 Green Chemistry principles, which are principally concerned with the prevention of pollution by waste minimisation and the avoidance of toxic and hazardous substances in the production and application of chemical products (Anastas and Eghbali 2010; Sheldon 2016). The innovation is potentially applicable to a range of areas, for example, leather but also packaging and textiles. The originator of this innovation is a co-author on this paper. According to the originator, the CEIP was easy to use, and the exercise useful. However, the outcome was less appropriate for products in this sector as compared with the Home Improvement sector. It was felt that some questions (2, 6-12; see Table 3$)$ could be adapted to be industry specific with the other questions remaining generic. Question 1,11 and 15 could perhaps have been linked and subdivided to distinguish between circular feedback loops (feedstock, reuse/remanufacture/recycle, use of 'scrappage', biodegradeability). Other suggestions that came up included: appropriate product lifetime; B2B contexts (for example, customers specify packaging requirements); applicability of various options e.g. leasing, traceability, repairing, reuse (not applicable for consumables such as chemicals).

\section{Discussion}

\section{Comparison with KCC}

The interview feedback showed a preference for the CEIP interface over the KCC. The CEIP was not compared with the MCI, which is not publicly available. Since the MCI builds on KCC, the findings are likely to be similar. One of the interviewees was part of the LIFE + Project (Granta Design 2015) which developed the MCI. In their interview, he was positive about the CEIP, specifically the question 'Can the usage status and identification of the product be established?' suggesting this as an area for further development.

\section{Application to case study}

The challenge exercise revealed that the tool could be adapted to other contexts, but that some customisation would be required, 
with a mix of 'generic' and specific questions. In particular, some options are more relevant in different contexts. In addition, the tool could do more to distinguish the 'tightness' of circularity (e.g. reuse/recycle).

One insight from the chemical industry is that the products are very general purposed so their circularity will be quite application dependent. Another is that $\mathrm{B} 2 \mathrm{~B}$ and $\mathrm{B} 2 \mathrm{C}$ contexts give different decision options for product decisions and innovators.

$\mathrm{CE}$ metrics and green chemistry principles are fundamental tools for designing new chemical processes and products of the future and will increasingly be an added value for industry and society (Sheldon 2016). Moreover, many of these technologies can contribute to the implementation of a sustainable $\mathrm{CE}$ as for our example.

\section{Comparison with Circular Economy Toolkit}

The Circular Economy Toolkit (CET) developed at the University of Cambridge (Evans and Bocken 2013) is a non-points online test that includes 33 questions that evaluate the improvement potential of products towards circularity. Although CET includes 18 more questions than CEIP, the distribution of the questions throughout the assessment and their nature (content) are quite similar. Both tools use product lifecycle stages to distribute the questions which present answer options that go from a least ideal' to a 'most ideal' circularity option. However, CEIP provides a more precise range of answer options than CET by allowing the tester the possibility to input percentages, linking them to specific scores and by showing explicitly which answer option is the most ideal towards circularity.

The outputs of the tests are similar in concept but different in presentation. CET includes a three-colour scale to identify generic improvement opportunities in each product lifecycle stage. CEIP presents a score in each stage and a final aggregated score for the product. A very interesting feature of CET is that it includes five types of evaluator which CEIP doesn't. However, these types are only asked for research purposes and are not linked to the quantity or nature of the Q\&A.

Features on both tests might suggest that (i) the evaluation of products in the CE is highly linked to the development of a clear understanding of the lifecycle of products and (ii) that their circularity couldn't be evaluated without acknowledging the multi-dimensional and systemic thinking nature of the $\mathrm{CE}$ model (from knowing their bill of materials to exploring different use/retail options, i.e. services). In fact, both tools simplify the measurement of circularity by design, and this could be critiqued as explained in the next section.

\section{Use of single metric}

It seems counterintuitive to use a single metric for a concept like circularity which is clearly multi-faceted. Product circularity depends on the lens through which it is viewed: impact measure (energy, $\mathrm{CO}_{2}$, equity); lifecycle stage (manufacture, use, 'end of life'); activity type (design, marketing, refurbishment). Gasparatos, El-Haram, and Horner (2009) argue that 'no single perspective can provide an adequate vision. They point out that aggregated metrics imply substitutability between dimensions. An alternative would have been a range of single-valued metrics, perhaps with criteria more directly linked to sustainability (e.g. $\mathrm{CO} 2$ emissions). To some extent, the CEIP does this by separating the impacts into lifecycle stages. The intention is that users are exposed to CE complexity gradually, and can drill down to the different stages as required. The case study also suggests a two-stage process, with generic and industry-specific questions. Further refinement is possible, including consideration of the interrelationships between dimensions (Gasparatos, El-Haram, and Horner 2009)

A single metric does have the advantages of communication and simplicity. An analogy is the 'Inclusive Wealth Index' (Duraiappah and Darkey 2012): a single metric covering economic, social and natural capital. It could be argued that circularity itself has a similar function; an umbrella term to simplify the underlying concepts and aid their diffusion.

\section{Does the metric reliably indicate improved environmental outcomes?}

There are two discussion points here: firstly, do the EMF CE principles reliably lead to better environmental outcomes; and secondly, does the CEIP successfully indicate adherence to the EMF CE principles?

With regard to the former, the EMF CE model appears to take as axiomatic that inner loops preserve most value. However, there are important questions to be asked about efficiency (Parkinson and Thompson 2003) and cultural attitudes to ownership (Appelgren and Bohlin 2015). In his comprehensive review, Tukker (2015) states of that product service systems are 'not the sustainability panacea'; for example, users of leased products tend to take less care of them, a concern shared by Scheepens, Vogtländer, and Brezet (2016). A study by Tabone et al. (2010) illustrates another difficulty. They derived a variety of metrics from green chemistry principles (some of which are similar to the EMF principles). These metrics are aggregated into a single score, which does show an overall qualified correlation with lifecycle impact. However, the lifecycle impact of biopolymers is generally underestimated and that of petroleum polymers overestimated. Scheepens, Vogtländer, and Brezet (2016) raise the additional concern that circular products that save consumers money may lead to undesirable rebound effects. van Kampen (2011) warns the circularity should not become an end in itself, advocating a systems thinking perspective which is resonant with comments made by Webster (2013).

The second concern raised is whether the CEIP successfully indicates adherence to the EMF CE principles (including systems thinking). A design decision was to use a multi-metric view covering different CE dimensions (material, energy or waste). Predefined options, including 'ideal circularity', are derived from EMF CE principles. These options depend on a number of assumptions which may not be appropriate for the product in question. For example, the question about recycling takes no account of whether the loop is closed (i.e. returned to the original manufacturer). The case study emphasises the need to address the tightness of the circularity loop. Some additional concerns are pointed out by Preston (2012). For example: the product may contain recently restricted chemicals (which might have been legal at the time of manufacturing); or EU-restricted chemicals (which might be legal outside of the EU). In addition, there is an issue of customer trust for recycled material. 
The values for the scores (weighting), although informed by expert interviews, could be sensitive to context. In addition, the selected variables were designed mainly for products in the Home Improvement sector, and the CEIP is not assumed to be reliable for products from other industries. The case study confirms this intuition, also suggesting a way forward through the use of specific questions, but also highlighting the complex interaction between questions, an aspect which again highlights the importance of systems thinking (Webster 2013).

\section{Does the metric lead to improved decision-making?}

The preceding discussion suggests that the CEIP should not be the sole source of decision-making, and that the circularity score is taken as indicative rather than definitive. However, the tool may improve decision-making through more widespread diffusion of circular thinking. To this extent ease of use is a crucial requirement. The prototype has been designed for an intermediate user who should have reasonable knowledge on: CE model; the product that is being assessed; and MS Excel. The most challenging requirement could be the second one because it demands a deep understanding of the performance and characteristics of the product in all its lifecycle stages. Participant 2 gave the following comments about this challenge: 'I think the biggest challenge is actually knowing or finding the data to put into the tool ... complicated supply chain(s)... what happens to products at end of life'.

This challenge could be seen as an advantage as it encourages users to engage more deeply with circularity considerations for their product. Participant 3 highlights this potential: 'training ... engineers, and other functions, to understand the levers for working on circularisation. This may be more important than the raw circularity score which may have limited direct use. As participant 6 commented 'right now those indicators won't be useful because our services are customer-driven and they ... don't ask for $[\mathrm{CE}]$ evaluations .... That is not to say that the output could not, in principle, be useful in the future - Participant 6 adding 'We also could use them [for] industry benchmarks'. Participant 7 remarked: 'They can help us to evaluate non-financial [and] long term aspects'. If this route is taken, then it is likely that more work will be needed to signpost the indicative nature of the tool's output.

\section{Future work}

Future work could include developing CE indicators for different industry sectors and product types. Even with the same $\mathrm{CE}$ variables, the questions that evaluate those variables, their weighting - and the optimal circularity options - could be varied depending on the context. According to Connett (2013) and WRAP (2015), the sectors that provide a suitable environment for applying those indicators are those with medium and long lived products: Automotive; Electricals and Electronics; Clothing and Textiles; and Food and Drink. Future CE tests should also enable comparison between products.

To address the criticisms of Scheepens, Vogtländer, and Brezet (2016), some element of customer value could be tested, with the aim to increase this while reducing eco-cost. Wider systemic considerations (Webster 2013) such as behavioural change (Kjaer et al. 2016) provide a further avenue to explore.
As discussed above, use of a single metric has clear advantages for simplicity and diffusion. However, more complex or ambiguous metrics may force users to engage more deeply with sustainability decisions, a position reminiscent of Morozov (2014) in his critique of frictionless 'solutionism'. Morovoz is an advocate of techniques that promote deliberation, rather than using algorithms to manipulate behaviour. This is a topic that deserves further attention.

\section{Conclusion}

The EMF CE model is an emergent paradigm for managing resources in a more efficient way to create a regenerative economy that has positive economic and environmental impacts. CE strategies can create resource efficiency, promote renewable energy and move towards zero waste. Yet transitioning from a Linear to a CE presents several challenges. The one tackled here is the need to measure CE product performance through indicators. CE indicators would allow businesses to monitor the implementation of CE strategies. Consequently, the research question was established: What are the possible characteristics of indicators for measuring the performance of products within the EMF CE model?

In order to probe this question, a prototype of $\mathrm{CE}$ indicators (CEIP) was developed. A multi-measure approach is taken, with a single aggregated metric for each lifecycle stage. This approach has several advantages: speed, simplicity; ease of diffusion; comprehensible metaphor. However, there are some limitations and challenges: hiding of complexity; potentially misleading results; superficial engagement with decision-making; and the reliance on context-specific assumptions. CEIP seems to work better with tangible goods that are built from/assembled (not transformed) from other tangible inputs/goods. In other words, products where a comprehensive Bill of Materials is available could be a good starting point. Suitable examples include: cars, computers, airplanes, etc. Further research might involve expanding CEIP to include products that result from chemical processes, i.e. paints. $\mathrm{CE}$ experts with backgrounds in research, consultancy, and supply chain management were interviewed. Their reaction is largely positive but further development is required, particularly the trade-off between simplicity and engagement; consideration of systemic factors and extension to other industries.

\section{Disclosure statement}

No potential conflict of interest was reported by the authors.

\section{Notes on contributors}

Steve Cayzer, $\mathrm{PhD}$, works as a senior teaching fellow at the University of Bath, UK. His main research interests include innovation (particularly sustainable innovation) including circular economy. He has published work on artificial immune systems, knowledge management, technology strategy and online education. Previous publications have appeared in Communications of the ACM, Journal of Web Semantics, On the Horizon and others.

Percy Griffiths is an Industrial Engineer with 10 years of experience in commercial and project management areas in the Ecotourism, Hospitality, Manufacturing and Business Consulting sectors. In 2011, he finished a Postgraduate Diploma in Project Management and in 2014 he completed an MSc in Innovation and Technology Management at the University of 
Bath (UK) where he developed an interest for the Circular Economy topic that lead him to a dissertation and journal publications about product circularity assessment.

Valentina Beghetto, $\mathrm{PhD}$ in Chemistry, works as a university senior assistant professor at University Ca' Foscari of Venice, Department of Molecular Sciences and Nanosystems, Italy. Her main research interests are in industrial organic synthesis, homogeneous catalysis, green tanning agents for leather production, characterization of organic compounds, biomass derived advanced materials. Previous publications have appeared in European Journal of Organic Chemistry, Organometallics, Applied Catalysis A, and others. Her research work is also the object of various European Patents.

\section{References}

Åkerman, Elin. 2016. "Development of Circular Economy Core Indicators for Natural Resources." Master of science thesis, KTH Royal Institute of Technology Stockholm.

Anastas, Paul, and Nicolas Eghbali. 2010. "Green Chemistry: Principles and Practice." Chemical Society Reviews 39 (1): 301-312.

Appelgren, Staffan, and Anna Bohlin. 2015. "Growing in Motion: The Circulation of Used Things on Second-hand Markets." Culture Unbound: Journal of Current Cultural Research 7 (1): 143-168.

Ayres, Robert U., and Allen V. Kneese. 1969. "Production, Consumption, and Externalities." The American Economic Review 59 (3): 282-297.

Beratan, Kathi K., Stanley J. Kabala, Shirley M. Loveless, Paula J. S. Martin, and Nancy P. Spyke. 2004. "Sustainability Indicators as a Communicative Tool: Building Bridges in Pennsylvania." Environmental Monitoring and Assessment 94 (1-3): 179-191.

Boulding, Kenneth. 1966. "The Economics of the Coming Spaceship Earth." In Environmental Quality in a Growing Economy, edited by $\mathrm{H}$. Jarrett, 3-14. Baltimore, MD: Resources for theFuture/Johns Hopkins University Press.

Braungart, M., and W. McDonough. 2009. Cradle to Cradle. London: Vintage Publishing.

Church, Cheyanne, and Mark M. Rogers. 2006. Designing for Results: Integrating Monitoring and Evaluation in Conflict Transformation Programs. Washington, DC: Search for Common Ground.

Connett, Paul. 2013. The Zero Waste Solution: Untrashing the Planet One Community at a Time. Chelsea: Green Publishing.

Duraiappah, Anantha Kumar, and Elorm Darkey. 2012. "Valuing Humanity's Life Support Systems: Inclusive Wealth and Satoyama Landscapes." Global Environmental Research 16: 137-144.

EMF (Ellen MacArthur Foundation). 2015. "Global Partners." http://www. ellenmacarthurfoundation.org/about/global-partners.

EMF (Ellen MacArthur Foundation). 2012. "Towards the Circular Economy Report Volume 1: An Economic and Business Rationale for an Accelerated Transition." https://www.ellenmacarthurfoundation. org/publications/towards-the-circular-economy-vol-1-an-economicand-business-rationale-for-an-accelerated-transition.

EMF (Ellen MacArthur Foundation). 2016. "The Circular Design Guide." http://circulardesignguide.com/.

EASAC (European Academies Science Advisory Council). 2016. "Indicators for a Circular Economy." http://www.easac.eu/fileadmin/ PDF_s/reports_statements/Circular_Economy/EASAC_Indicators_ web_complete.pdf.

European Commission. 2015. “Towards a Circular Economy." Accessed December 20. http://ec.europa.eu/priorities/jobs-growth-investment/ circulareconomy/index_en.htm

Erkman, S. 1997. "Industrial Ecology: An Historical View." Journal of Cleaner Production 5 (1-2): 1-10.

Evans, J., and N. Bocken. 2013. Circular Economy Toolkit. Cambridge Institute for Manufacturing. http://circulareconomytoolkit.org/.

Franklin-Johnson, Elizabeth, Frank Figge, and Louise Canning. 2016. "Resource Duration as a Managerial Indicator for Circular Economy Performance." Journal of Cleaner Production 133 (October): 589-598.

Gasparatos, Alexandros, Mohamed El-Haram, and Malcolm Horner. 2009. "The Argument Against a Reductionist Approach for Measuring Sustainable Development Performance and the Need for Methodological Pluralism." Accounting Forum, 33 (3): 245-256. Elsevier.
Geng, Yong, Joseph Sarkis, Sergio Ulgiati, and Pan Zhang. 2013. "Measuring China's Circular Economy.” Science 339 (6127): 1526-1527.

Geoffrey, L., and C. Todd. 2001. "Defining Thresholds for Freshwater Sustainability Indicators Within the Context of South African Water Resource Management." Second WARFSA/WaterNet Symposium, Cape Town, South Africa, October 30-31.

Ghisellini, P., C. Cialani, and S. Ulgiati. 2016. "A Review on Circular Economy: The Expected Transition to a Balanced Interplay of Environmental and Economic Systems." Journal of Cleaner Production 114: 11-32.

Giurco, Damien, Anna Littleboy, Thomas Boyle, Julian Fyfe, and Stuart White. 2014. "Circular Economy: Questions for Responsible Minerals, Additive Manufacturing and Recycling of Metals." Resources 3 (2): 432 453.

Granta Design. 2015. "Resource Efficiency Collaborations." http://www. grantadesign.com/company/collaborations/resource.htm\#life.

Gregson, Nicky, and Mike Crang. 2015. "From Waste to Resource: The Trade in Wastes and Global Recycling Economies." Annual Review of Environment and Resources 40: 151-176.

Kjaer, Louise Laumann, Aris Pagoropoulos, Jannick H. Schmidt, and Tim C. McAloone. 2016. "Challenges When Evaluating Product/ServiceSystems Through Life Cycle Assessment." Journal of Cleaner Production 120: 95-104.

Morozov, Evgeny. 2014. To Save Everything, Click Here: The Folly of Technological Solutionism. London: Penguin.

Nappi, V., and H. Rozenfeld. 2015. "The Incorporation of Sustainability Indicators into a Performance Measurement System." Procedia CIRP 26: 7-12.

NCRM (National Centre for Research Methods). 2015. "How Many Qualitative Interviews is Enough?" Accessed December 10. http:// eprints.ncrm.ac.uk/2273/4/how_many_interviews.pdf

Parkinson, H. J., and G. Thompson. 2003. "Analysis and Taxonomy of Remanufacturing Industry Practice." Proceedings of the Institution of Mechanical Engineers, Part E: Journal of Process Mechanical Engineering 217 (3): 243-256

Pauli, Gunter. 2010. "The Blue Economy." Our Planet: 24-27.

Preston, F. 2012. A Global Redesign? Shaping the Circular Economy. Chatham: House Briefing Paper. EERG BP 2012/02.

Rahdari, A. H., and A. A. Anvary Rostamy. 2015. "Designing a General Set of Sustainability Indicators at the Corporate Level." Journal of Cleaner Production 108 (Part A): 757-771.

Scheepens, A. E., J. G. Vogtländer, and J. C. Brezet. 2016. “Two Life Cycle Assessment (LCA) Based Methods to Analyse and Design Complex (Regional) Circular Economy Systems. Case: Making water Tourism More Sustainable." Journal of Cleaner Production 114: 257-268.

Sheldon, R. A. 2016. "Green chemistry and resource efficiency: towards a green economy." Green Chem 18 (11): 3180-3183.

Stahel, Walter R. 2010. The performance economy. vol. 572. London: Palgrave Macmillan.

Sustainable Brands. 2013. "Entropic Overhead: Measuring the Circular Economy." http://www.sustainablebrands.com/news_and_views/new_ metrics/entropic-overhead-measuring-circular-economy

Tabone, Michaelangelo D., J. James Cregg, Eric J. Beckman, and Amy E. Landis. 2010. "Sustainability Metrics: Life Cycle Assessment and Green Design in Polymers." Environmental Science \& Technology 44 (21): 8264-8269.

Tukker, Arnold. 2015. "Product services for a resource-efficient and circular economy-a review." Journal of Cleaner Production 97: 76-91.

van Kampen, Michela. 2011. "Measuring circularity: putting the cart before the horse?". Phillips Innovation Services. http://www.innovationservices. philips.com/news/measuring-circularity

Vogtländer, Joost G., Han C. Brezet, and Charles F. Hendriks. 2001. “The Virtual Eco-costs '99 A Single LCA-based Indicator for Sustainability and the Eco-costs-Value Ratio (EVR) Model for Economic Allocation." The International Journal of Life Cycle Assessment 6 (3): 157-166.

Webster, Ken. 2013. "Missing the Wood for the Trees: Systemic Defects and the Future of Education for Sustainable Development." Curriculum Journal 24 (2): 295-315.

WRAP. 2015. "WRAP and the Circular Economy." Accessed December 20. http://www.wrap.org.uk/content/wrap-and-circular-economy 